\title{
Pelatihan Rhythmic Auditory Stimulation (RAS) dan Visual Cue Training (VCT) Memperbaiki Kemampuan Berjalan Pasien Stroke
}

\author{
${ }^{1}$ Jerry Maratis, ${ }^{2}$ Ilham Fatria, ${ }^{3}$ Abdul Chalik Meidian, ${ }^{4}$ Abdurrasyid, ${ }^{5}$ La Ode \\ Muhammad Gustrin Syah
}

\author{
Fakultas Fisioterapi, Universitas Esa Unggul, Jakarta \\ J1. Arjuna Utara No. 9 Kebon Jeruk Jakarta Barat Jakarta -11510 \\ jerry.maratis@esaunggul.ac.id
}

Tanggal Submisi: 7 Juli 2020; Tanggal Penerimaan: 14 Juli 2020

\begin{abstract}
ABSTRAK
Tujuan: Mempelajari pengaruh pelatihan rhythmic auditory stimulation (RAS) terhadap visual cue training (VCT) untuk memperbaiki kemampuan berjalan pasien stroke. Metode: Penelitian bersifat quasi experimental yang melibatkan 20 sampel dengan pembagian 10 sampel kontrol hanya VCT dan 10 sampel perlakuan RAS dan VCT, kemampuan berjalan diukur menggunakan dynamic gait index (DGI). Hasil: Pada kelompok kontrol di uji dengan paired sample test didapatkan nilai sebelum 14,80 $\pm 1,61$ dan sesudah $15,10 \pm 1,28, \mathrm{p}=0,193(\mathrm{p}>0,05)$ artinya tidak ditemui perubahan kemampuan berjalan pasien stroke. Pada kelompok perlakuan diuji dengan wilcoxon sign rank test didapatkan nilai sebelum 12,90 $\pm 2,42$ dan sesudah $14,10 \pm 1,66, \quad \mathrm{p}=0,016(\mathrm{p}<0,05)$ artinya terdapat perubahan kemampuan berjalan pasien stroke. Pengaruh antara kedua kelompok diuji dengan mann whitney $u$ test didapatkan nilai $\mathrm{p}=0,030(\mathrm{p}<0,05)$ artinya ada perbedaan kemampuan berjalan. Kesimpulan: Pelatihan rhythmic auditory stimulation dan visual cue training berpengaruh signifikan terhadap perbaikan kemampuan berjalan pasien stroke.
\end{abstract}

Kata Kunci: visual cue training exercise, rhythmic auditory stimulation exercise, dynamic gait index, kemampuan berjalan, pasien stroke.

\section{ABSTRACT}

Objective: To study the effect of the rhythmic auditory stimulation (RAS) exercise (RAS) with visual cue training (VCT) for improving walking ability stroke patients. Method: This research was Quasi Experimental and the walking ability was measured with dynamic gait index (DGI). The sample consisted of 20 samples devided into 2 groups: 10 samples with VCTE (control group) and 10 samples with RAS and VCT (treatment groups). Results: For control group was tested with paired sample t-test obtained before exercise 14,80 \pm 1.61 and after 15,10 \pm $1.28, \mathrm{p}=0,193(\mathrm{p}>0.05)$ it's mean there was no effect in the walking ability for stroke patients. Treatment group was tested with Wilcoxon sign rank test obtained before exercise 12,90 \pm 2.42 and after 14,10 $\pm 1.66, p=0,016$ it's mean there was an effect for improving in walking ability for stroke patients. To see the differences between two groups were tested with Mann Whitney $u$ test obtained value $\mathrm{p}=0,030$ it's mean there were a differences effect between treatment groups and the control group. Conclusion: Rhythmic auditory stimulation exercise with visual cue training had significantly effect to improve walking ability for stroke patients.

Keywords: visual cue training exercise, rhythmic auditory stimulation exercise, dynamic gait index, ability to walk, stroke patients.

\section{PENDAHULUAN}

Indonesia dalam beberapa dasawarsa terakhir menunjukan prevalensi pada penyakit tidak menular meningkat. Stroke, salah satu bagian dari penyakit tidak menular memberikan dampak lain akibat meningkatnya prevalensi tersebut, yaitu meningkatnya jumlah disabilitas atau kecacatan pada masyarakat yang mengalami gangguan gerak dan fungsi termasuk pada kemampuan berjalan. 
Berdasarkan World Health Organization (2018), stroke penyebab kematian terbanyak di dunia setelah penyakit jantung. Pada tahun 2016 terjadi kematian sebanyak 15,2 juta penduduk karena stroke (World Health Organization, 2018). Menurut hasil Riset Kesehatan Dasar 2018, stroke bagian dari penyakit tidak menular di Indonesia. Prevalensi stroke di Indonesia 10,9 per 1.000 penduduk. Angka itu naik dibandingkan Riskesdas 2013 yang sebesar 7 per 1.000 penduduk (Kementerian Kesehatan, 2018).

Walaupun penyakit stroke adalah penyakit mematikan, pada kenyataannya ada juga dari penderitanya dapat pulih sempurna, namun sebagian besarnya meninggalkan gejala-gejala sisa. Gejala yang muncul berupa gangguan motorik, sensorik, gangguan keseimbangan, postural kontrol, dan gangguan reflek yang terjadi akibat adanya gangguan atau kerusakan sirkulasi darah di otak. Gejalagejala tersebut berdampak pada terjadinya keterbatasan gerak, perubahan struktur tubuh, gangguan bersosialisasi dengan lingkungan serta keterbatasan kemampuan aktivitas fungsional individu sehari-hari (Irfan, 2010; Nisa \& Maratis, 2019).

Untuk menjawab tantangan tersebut, diperlukan penanganan yang optimal secara khusus dan melibatkan berbagai disiplin ilmu termasuk fisioterapi. Fisioterapi merupakan salah satu bagian integral dalam pelayanan kesehatan yang betujuan untuk meningkatkan kapasitas fisik dan kemampuan fungsional berdasarkan kemampuan yang dimiliki sesuai dengan kewenangannya.

Fisioterapi pada stroke berperan dalam mengembangkan, memelihara dan memulihkan gerak dan fungsi dengan pelatihan motorik berdasarkan pemahaman terhadap patofisiologi, neurofisiologi, kinematik dan kinetik dari gerak normal, proses kontrol gerak dan motor learning serta penanganan dengan pemanfaatan elektroterapeutis. Oleh karena itu, dibutuhkan pelayanan fisioterapi untuk pelatihan berjalan karena pada pasien stroke hal ini merupakan yang utama karena merupakan suatu kemampuan lokomosi yang sangat penting dalam melakukan aktivitas sehari-hari (Irfan, 2010).
Dalam penelitian ini penulis menggunakan pengukuran dynamic gait index (DGI) untuk mengevaluasi kemampuan berjalan pasien stroke (Ryan, 2020). Adapun salah satu bentuk terbaru untuk latihan berjalan adalah rhythmic auditory stimulation (RAS) (Maratis, Angkasa, Malabay, \& Amir, 2019). RAS adalah pelatihan dengan melibatkan penggunaan isyarat sensorik auditori yang berirama dari sistem motorik dengan model sinkronisasi gelombang (entrainment) (Maratis, Suryadhi, \& Irfan, 2015). Proses neuro rehabilitasi melibatkan gerakan berulang-ulang dengan pola ritmis sangat efektif dalam pelatihan kemampuan berjalan untuk pasien stroke, dan memfasilitasi perbaikan jangka panjang pada sensorimotor korteks yang berkaitan dengan pembelajaran motorik (Suh et al., 2014).

Isyarat auditori berirama tersebut dapat menghasilkan respon motorik menjadi sinkron terhadap waktu yang stabil layaknya oscillator coupling. Irama dijadikan sebagai referensi waktu antisipatif dan berkesinambungan dimana setiap gerakan dipetakan dalam model (template) sementara yang stabil. Mekanisme dari penyelarasan gerakan fisiologis antara irama auditori dengan respon motorik berfungsi sebagai mekanisme coupling dalam membuat acuan regulasi dan kestabilan pada pola berjalan (Thaut et al., 2007).

Dalam praktik klinis neurorehabilitasi, RAS sering digunakan untuk meningkatkan kemampuan berjalan pasien stroke. Fisioterapis memberikan isyarat auditori dengan bertepuk tangan, menghitung keras, atau dengan secara verbal menekankan perintah, untuk melangkahkan kaki dimulai dari kaki parese. RAS bermanfaat terhadap kemampuan berjalan pasien stroke (Roerdink et al., 2009).

Hal ini karena isyarat auditori berirama memfasilitasi untuk membuat perencanaan gerak yaitu berdasarkan motor relearning dari informasi sensorik dan somatosensory feedback (Cha, Yuri. Kim, Young. Chung, 2014). RAS dapat meningkatkan kecepatan berjalan, ketepatan kontrol waktu, serta kelancaran mencapai gerakan. Hal tersebut dikarenakan stimulasi auditori merupakan sarana untuk 
meningkatkan rangsangan neuron motorik spinal melalui jalur retikulospinalis, sehingga menyebabkan efisiensi waktu yang dibutuhkan otot untuk meresepon perintah motorik (Son \& Hyo Jeong Ryu, 2016).

Dalam proses rehabilitasi yang melibatkan penggunaan RAS terbukti meningkatkan kemampuan berjalan dalam hal ini yaitu velocity, stride length, dan cadence bila diterapkan pada pasien dengan cerebral palsy, stroke, dan parkinson (berbagai jenis penyakit neurologis) (Kim, Kwak, \& Park, 2012). Pengaruh isyarat sensorik ritmik dalam berjalan dinamik memiliki relevansi besar dalam rehabilitasi neurologi. Isyarat auditori memberikan efek positif terhadap variasi karakter jalan pada pasien dengan penyakit parkinson, stroke, dan hemiparesis (Sejdic, Fu, Pak, Fairley, \& Chau, 2012).

Selain menggunakan isyarat auditori, beberapa penelitian telah menunjukkan bahwa isyarat visual lebih efektif dalam memicu penyesuaian gait serta meningkatkan kemampuan berjalan pada pasien stroke. Informasi visual merupakan sumber informasi yang paling baik dalam mengontrol jalan dan tampaknya ada ketergantungan dalam mempertahankan stabilitas dinamik pasien stroke pada visualisasi (Hollands et al., 2013).

Visual cue training (VCT) merupakan pelatihan dengan menggunakan isyarat eksternal yaitu adaptasi visual untuk meningkatkan motor control selama berjalan dengan memfasilitasi pasien memodifikasi panjang langkah berdasarkan informasi sensorik visual yang telah disediakan (Amatachaya, Keawsutthi, Amatachaya, \& Manimmanakorn, 2009).

Isyarat eksternal visual merupakan informasi yang membantu gerakan motorik subjek secara efisien dalam mengatur ulang gerakan pasien stroke dan menghasilkan tingkat kemampuan berjalan yang lebih baik daripada penentuan oleh pasien stroke sendiri walaupun terdapat kerusakan pada sistem motor dan sensorik (Amatachaya et al., 2009). Berdasarkan pemahaman mengenai motor control dari sistem lokomosi menunjukkan bahwa isyarat eksternal yakni informasi visual yang merupakan salah satu sumber informasi yang terpenting dan penting digunakan ketika berjalan (Hollands, Pelton, Tyson, Hollands, \& Vliet, 2012).
Isyarat visual menyediakan informasi spasial, sehingga membantu subjek berjalan dengan panjang langkah yang baik, namun dengan kecepatan berjalan dan cadence rendah (Amatachaya et al., 2009). Posisi spasial untuk menentukan posisi penempatan kaki yang diperlukan adalah kunci untuk memahami mengapa adaptasi gait lebih efektif dalam respon terhadap visual stepping stones (Bank, Roerdink, \& Peper, 2011).

Ketika kita dapat melihat, terdapat penukaran akurasi kecepatan/speed accuracy trade- off, yaitu pada saat langkah cepat terjadi kesalahan yang lebih besar dan bervariasi dibandingkan langkah yang lambat (Reynolds \& Day, 2005).

\section{METODE PENELITIAN}

Metode penelitian bersifat kuasi eksperimental yang bertujuan untuk mengetahui perbaikan kemampuan berjalan menggunakan kombinasi pelatihan RAS dan VCT. Metode penelitian dilakukan dengan pre-test post-test control group design. Penelitian ini dibagi menjadi dua kelompok. Adapun sampel secara keseluruhan sebanyak 20 orang. Pembagian sampel dilakukan secara acak dengan jumlah masing-masing kedua kelompok sebanyak 10 sampel. Kelompok kontrol hanya diberikan program pelatihan VCT, sedangkan kelompok perlakuan diberikan kombinasi pelatihan RAS dan VCT. Pemberian program pelatihan RAS dan VCT dilakukan selama 5 minggu dengan frekuensi 3 kali seminggu.

Kriteria inklusi sampel yang kami gunakan sebagai berikut: laki-laki atau perempuan usia 39-75 tahun, fase akhir stroke (1-5 tahun setelah stroke iskemik atau hemoragik dengan gejala / gejala hemisfer awal), skala Ashworth derajat 1-2, pengukuran berg balance scale (BBS) $\geq 30$, sudah mampu berjalan mandiri atau menggunakan alat bantu, mengerti dan menyetujui untuk tujuan penelitian. Kriteria penolakan sebagai berikut: kondisi gangguan visual, pendengaran, kardiopulmonal, koordinasi, proprioseptif, muskuloskeletal yang mempengaruhi keseimbangan, nilai modified rankin scale (MRS) <2 atau >3 menggunakan, etiologi stroke iskemik atau hemoragik atau 
perdarahan subarachnoid tanpa dampak hemispher, disfungsi serebral, gangguan neurologis selain stroke, memiliki kondisi lain yang dapat mempengaruhi berjalan seperti rasa sakit atau pembengkakan di persendian tungkai bawah.

Alat ukur kemampuan berjalan DGI adalah indeks berjalan dinamis yang mengklasifikasikan tingkat keterampilan fungsional berjalan subjek. Hal ini mengharuskan subjek untuk melakukan tugas yang menuntut tingkat keseimbangan tinggi dilihat 8 aspek penilaian. Dengan interpretasi skor $<19 / 24=$ prediksi jatuh pada pasien stroke dan $>22 / 24=$ ambulator yang aman (Ryan, 2020).

Delapan aspek penilaian kemampuan untuk berjalan meliputi:

1) Berjalan

2) Mengubah kecepatan berjalan

3) Berjalan dengan melihat ke kiri dan ke kanan

4) Berjalan dengan melihat ke atas dan ke bawah

5) Berjalan dengan melakukan putaran $180^{\circ}$

6) Berjalan dengan melangkahi kotak sepatu

7) Berjalan di sekitar kotak sepatu

8) Berjalan naik turun tangga.

\section{HASIL PENELITIAN}

\begin{tabular}{|c|c|c|c|}
\hline & $\begin{array}{l}\text { Kelompok } \\
\text { Kontrol } \\
(\mathbf{n}=10)\end{array}$ & $\begin{array}{l}\text { Kelompok } \\
\text { Perlakuan } \\
(\mathrm{n}=10)\end{array}$ & \\
\hline Usia & Jumlah & Jumlah & \\
\hline 39-60 tahun & 4 & 6 & \\
\hline $61-75$ tahun & 6 & 4 & \\
\hline \multicolumn{4}{|l|}{ Jenis Kelamin } \\
\hline Laki-Laki & 6 & 7 & \\
\hline Perempuan & 4 & 3 & \\
\hline \multicolumn{4}{|l|}{ Etiologi Stroke } \\
\hline Ischemia & 8 & 6 & \\
\hline Haemoragic & 2 & 4 & \\
\hline $\begin{array}{l}\text { Nilai dynamic } \\
\text { gait index (DGI) }\end{array}$ & rerata $\pm s d$ & rerata \pm sd & Homogenitas \\
\hline Sebelum & $14,80 \pm 1,61$ & $12,90 \pm 2,42$ & 0,54 \\
\hline Sesudah & $15,10 \pm 1,28$ & $14,10 \pm 1,66$ & - \\
\hline Selisih & $0,30 \pm 0,67$ & $1,20 \pm 1,03$ & - \\
\hline
\end{tabular}

Dari penelitian yang telah kami lakukan, yaitu membagi kategori usia 39-60 tahun pada kelompok kontrol 4 sampel dan perlakuan 6 sampel sedangkan pada kategori usia 61-75 tahun pada kelompok kontrol 6 sampel dan perlakuan 4 sampel. Jika kita perhatikan dari segi usia memang banyak kasus stroke dialami pada usia lanjut. Berdasarkan jenis kelamin laki-laki pada kelompok kontrol 6 sampel dan perlakuan 7 sampel, serta jenis kelamin perempuan pada kelompok kontrol 4 sampel dan perlakuan 3 sampel. Didominasi oleh jenis kelamin pria dikarenakan faktor konsumsi rokok yang tinggi pada pria di Indonesia.

Hasil dari nilai DGI menunjukkan ada perbedaan selisih kemampuan berjalan antara kedua kelompok sampel. Pada kelompok kontrol diperoleh nilai $0,30 \pm 0,67$ poin dimana tidak terlihat besar pengaruh yang diperoleh dari program pelatihan VCT, sedangkan kelompok perlakuan terdapat perubahan

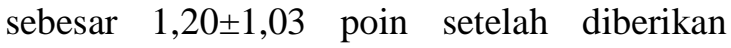
kombinasi pelatihan RAS dan VCT.

Melihat hasil DGI pada Tabel 2, kami mengujikan dengan perangkat lunak komputer SPSS untuk melihat angka signifikansi pada masing-masing kelompok. Dapat dilihat pada Tabel 2. Pada kelompok kontrol (hipotesis 1) diperoleh nilai $p=0,193(p>0,05)$ maka tidak ada perbaikan kemampuan berjalan setelah diberikan pelatihan VCT pada pasien stroke. Sedangkan pada kelompok perlakuan (hipotesis 2) diperoleh nilai $\mathrm{p}=0,016(\mathrm{p}<0,05)$ maka terdapat perbaikan kemampuan berjalan setelah diberikan kombinasi pelatihan RAS dan VCT. Melihat perbedaan pengaruh antar kedua kelompok (hipotesis 3) kami menilai dari data selisih dengan uji mann-whitney $u$ test diperoleh nilai $\mathrm{p}=0,03 \quad(\mathrm{p}<0,05)$ maka terlihat ada perbedaan pengaruh yang dihasilkan antara kedua kelompok.

\section{PEMBAHASAN}

\section{Pelatihan Visual Cue Training tidak dapat memperbaiki kemampuan berjalan pasien stroke}


Tabel 2. Data hasil uji hipotesa kelompok kontrol dan perlakuan

\begin{tabular}{ccccc}
\hline Kelompok & Uji Hipotesa & $\begin{array}{c}\text { Nilai DGI sebelum } \\
(\text { rerata } \pm \text { sd) }\end{array}$ & $\begin{array}{c}\text { Nilai DGI Sesudah } \\
(\text { rerata } \pm \text { sd) }\end{array}$ & $\begin{array}{c}\text { Nilai } \\
\text { Signifikan }\end{array}$ \\
\hline Kontrol (VCT) & $\begin{array}{c}\text { Paired sample } \\
\text { t-test }\end{array}$ & $14,80 \pm 1,61$ & $15,10 \pm 1,28$ & 0,193 \\
$\begin{array}{c}\text { Perlakuan } \\
\text { (kombinasi }\end{array}$ & $\begin{array}{c}\text { Wilcoxon sign } \\
\text { rank test }\end{array}$ & $12,90 \pm 2,42$ & $14,10 \pm 1,66$ & 0,016 \\
RAS \& VCT) & & & \\
Perbedaan data \\
selisih antar \\
kedua \\
kelompok
\end{tabular}

Visual memegang peranan penting dalam sistem sensorik. Keseimbangan akan terus berkembang sesuai umur, mata akan membantu agar tetap fokus pada titik utama sebagai mediasi mempertahankan keseimbangan dan sebagai monitor tubuh selama melakukan gerakan statik ataupun dinamik (Irfan, 2010).

Peneliti menyimpulkan bahwa pada penelitian ini pelatihan VCT tidak dapat meningkatkan kemampuan berjalan dikarenakan adanya karakteristik sampel yang usianya rata-rata diatas 50 tahun.

Salah satu faktor yang mempengaruhi keseimbangan adalah usia. Pada saat usia lanjut maka akan berkurangnya sel reseptor pada organ vestibuler, gangguan persepsi sensorik, berkurangnya kekuatan otot sehingga meningkatnya waktu yang diperlukan untuk bereaksi dalam masa pemulihan (Kalisch, Kattenstroth, Noth, Tegenthoff, \& Dinse, 2011).

Selain hal tersebut, yang menjadi salah satu faktor adalah pada sampel kelompok kontrol lebih banyak didapatkan stroke dengan tipe iskemik sedangkan untuk pemulihan pascastroke lebih lama, stroke hemoragik lebih baik peningkatan fungsionalnya dibanding stroke Iskemik (R. Teasell, Hussein, Mcclure, \& Meyer, 2014).

\section{Kombinasi pelatihan rhythmic auditory stimulation exercise dan visual cue training memperbaiki kemampuan berjalan pasien stroke}

Sidaway et al. (2006), menyatakan bahwa pelatihan VCT pada pasien stroke untuk melangkah di atas isyarat visual dapat meningkatkan parameter gait, kemampuan untuk melangkah melewati objek, dan ketahanan berjalan. Isyarat visual menyediakan target gerakan, mengaktivasi jalur cerebellar visual-motor. Penggunaan isyarat visual jangka panjang dapat menyebabkan perubahan dalam kontrol berjalan dari jalur cortical- motor ke cerebellar visual-motor. Perubahan ini yang mendukung peningkatan pola jalan untuk setidaknya 1 bulan setelah isyarat visual tersebut dihilangkan (Sidaway, Anderson, Danielson, Martin, \& Smith, 2006).

Penambahan pelatihan RAS dapat menginduksi peningkatan fungsi motorik pada pasien stroke kronik yang diikuti dengan meningkatnya eksitabilitas traktus kortikospinal dan modifikasi korteks motorik yang dapat diasosiasikan dengan plastisitas otak (Sanchez, JG. Amenguel, JL., Rojo, 2013). Penelitian terbaru menekankan pentingnya informasi sensorik perifer dan penjalaran input ke bawah dalam membentuk fungsi central pattern generator $(C P G)$ dan secara khusus menunjukkan mekanism plastisitas pascalesi sehingga terjadi perbaikan otak (Juan-Manuel et al., 2011).

RAS memandu pasien untuk menginjakkan kaki mereka saat mereka berjalan dan secara bersamaan mendengarkan isyarat auditori eksternal, mensinkronkan waktu kontak kaki dengan suara (Cha, Yuri. Kim, Young. Chung, 2014). Penelitian Ford et al. (2010) membuktikan bahwa RAS dapat meningkatkan kecepatan berjalan, stride length dan cadence pada pasien Parkinson (Ford et al., 2010). 
Elemen kunci RAS adalah fenomena penyelarasan auditori, yaitu kemampuan tubuh menyinkronkan gerakannya secara ritmis. Aktivitas auditori eksternal dimediasi oleh pembentukan persepsi internal dibawah sadar pada level subkortikal dan dapat menaikkan dan membangkitkan kepekaan neuron motorik spinal yang diperantarai oleh sirkuit auditorymotor pada level retikulospinal. Irama dapat mengorganisasi gait seseorang dan meningkatkan pola berjalan (Maratis, 2020).

\section{Ada perbedaan pengaruh kombinasi pelatihan rhythmic auditory stimulation dan visual cue training memperbaiki kemampuan berjalan pasien stroke}

Untuk menguatkan hasil penelitian ini belum ada jurnal yang melakukan penelitian mengenai kombinasi antara pelatihan RAS dan VCT sebelumnya. Akan tetapi peneliti berpendapat dengan mengacu konsep plastisitas otak dan sistem saraf. Plastisitas merupakan kemampuan dari sistem saraf pusat untuk beradaptasi terhadap kebutuhan fungsional.

Stimulasi visual memainkan peran penting pada semua strategi reaktif, prediktif dan antisipasi karena menyediakan informasi spatiotemporal mengenai penempatan yang sangat tepat (Higuchi, 2013). Dalam penelitian ini stimulasi visual dikombinasikan dengan terapi dibantu dengan musik (RAS) yang mana akan menyebabkan induksi peningkatan fungsi motorik pada pasien stroke dan diikuti meningkatnya eksitabilitas traktus kortikospinal serta modifikasi korteks motorik yang kemudian diasosiasikan dengan plastisitas otak (Sanchez, JG. Amenguel, JL., Rojo, 2013).

Neuroplastisitas dapat terjadi dalam bentuk cross model reassignment, yang membolehkan satu jenis input panca indera untuk secara keseluruhan mengganti kerusakan lainnya (Irfan, 2010). Penelitian tersebut menguatkan teori bahwa pendekatan model recovery pascastroke dengan multisensorik akan mempercepat perbaikan (R. W. Teasell, Foley, Bhogal, \& Speechley, 2003).

Kendati demikian peneliti tidak dapat memaparkan secara detail proses perkembangan dari hasil intervensi pada level neuroanatomi otak karena terbatasnya alat ukur yang digunakan. Perkembangan tersebut dapat melalui alat Positron Emission Tomography (PET) dan functional Magnetic Resonance Imaging (fMRI) yang memungkinkan untuk mengamati aktivitas otak pada manusia yang hidup tanpa membuka otaknya.

\section{KESIMPULAN DAN SARAN}

Ada pengaruh yang signifikan kombinasi pelatihan RAS terhadap VCT memperbaiki kemampuan berjalan pasien stroke yang dilakukan selama 5 minggu sebanyak 3 kali seminggu pelatihan RAS dan VCT. Total sebanyak 15 kali pelatihan kombinasi RAS dan VCT menunjukkan adanya perubahan yang signifikan pada kemampuan berjalan.

Berdasarkan hasil penelitian, belum adanya perubahan terhadap kemampuan berjalan jika hanya diberikan pelatihan VCT saja tanpa penambahan pelatihan RAS. Diharapkan penelitian ini dapat dilanjutkan sehingga mendapatkan hasil yang lebih efektif dari sebelumnya.

\section{UCAPAN TERIMA KASIH}

Peneliti menyadari tanpa bantuan dan dukungan dari berbagai pihak penyusunan penelitian ini tidak dapat berjalan baik. Dalam hal ini peneliti telah banyak menerima bantuan dan bimbingan moril dan materiil. Maka tim peneliti mengucapkan terimakasih kepada dosen dan teman sejawat yang telah berkenan membagi ilmu dan pengalaman.

Peneliti juga mengucapkan terima kasih kepada seluruh staff Klinik Karmel yang telah membantu dalam sarana dan prasarana penelitian, serta para pasien stroke di Klinik Karmel dan Klub Stroke Karmel yang sudah berkenan menjadi responden dalam penelitian. Tidak lupa ucapan terima kasih kepada Universitas Esa Unggul Fakultas Fisioterapi yang telah memberikan izin terkait kegiatan penelitian ini.

\section{DAFTAR PUSTAKA}

Amatachaya, S., Keawsutthi, M., Amatachaya, P., \& Manimmanakorn, N. (2009). Effects of external cues on gait performance in independent ambulatory incomplete spinal cord injury patients. Spinal Cord, 47(9), 668-673. 
https://doi.org/10.1038/sc.2008.168.

Bank, P. J. M., Roerdink, M., \& Peper, C. E. (2011). Comparing the efficacy of metronome beeps and stepping stones to adjust gait: steps to follow !, 159-169. https://doi.org/10.1007/s00221-0102531-9.

Cha, Yuri. Kim, Young. Chung, Y. (2014). Immediate Effects of Rhythmic Auditory Stimulation with Tempo Changes on Gait in Stroke Patients, (2), 4-7.

Ford, M. P., Malone, L. A., Nyikos, I., Yelisetty, R., Mp, A. F., La, M., Yelisetty, R. (2010). Gait Training With Progressive External Auditory Cueing in Persons With Parkinson's Disease. YAPMR, 91(8), 1255-1261. https://doi.org/10.1016/j.apmr.2010.04.0 12

Higuchi, T. (2013). Visuomotor control of human adaptive locomotion: understanding the anticipatory nature, 4(May), 1-9.

https://doi.org/10.3389/fpsyg.2013.00277

Hollands, K. L., Pelton, T. A., Tyson, S. F., Hollands, M. A., \& Vliet, P. M. Van. (2012). Gait \& Posture Interventions for coordination of walking following stroke: Systematic review. Gait \& Posture, 35(3), 349-359. https://doi.org/10.1016/j.gaitpost.2011.10 .355

Hollands, K. L., Pelton, T., Wimperis, A., Whitham, D., Jowett, S., \& Sackley, C. (2013). Visual cue training to improve walking and turning after stroke : a study protocol for a multi-centre, single blind randomised pilot trial. Trials, 14(1), 111. https://doi.org/10.1186/1745-621514-276

Irfan, M. (2010). Fisioterapi Bagi Insan Stroke. Yogyakarta: Graha Ilmu.

Juan-Manuel, B.-L., Horno, S. M., Bermejobosch, I., Moreno, J. C., Pons, J. L., Farina, D., ... Rea, M. (2011).
Rehabilitation of gait after stroke: a review towards a top-down approach. J.Neuroeng Rehabil., 66(December), 119.

Kalisch, T., Kattenstroth, J., Noth, S., Tegenthoff, M., \& Dinse, H. R. (2011). Rapid Assessment of Age-Related Differences in Standing Balance. Aging Research,2011. https://doi.org/10.4061/2011/160490

Kementerian Kesehatan, K. (2018). Laporan Nasional RISKESDAS 2018.

Kim, S. J., Kwak, E., \& Park, E. S. (2012). Differential effects of rhythmic auditory stimulation and neurodevelopmental treatment/Bobath on gait patterns in adults with cerebral palsy: A randomized controlled trial. Clinical Rehabilitation, 904-914.

https://doi.org/10.1177/02692155114346 48

Maratis, J. (2020). Pengaruh Senam Rhythmic Auditory Stimulation ( RAS ) Dengan Kemampuan Berjalan Lansia Di Desa Kohod Kabupaten Tangerang. Jurnal Fisioterapi, 20, 25-31.

Maratis, J., Angkasa, D., Malabay, \& Amir, T. L. (2019). Peningkatan Status Kesehatan Dengan Senam Rhytmic Auditory Stimulation Dan Gizi Seimbang Lansia Di Desa Kohod. IKRAITH-ABDIMAS, 2(1), 26-32.

Maratis, J., Suryadhi, N. T., \& Irfan, M. (2015). Perbandingan Antara Visual Cue Training Dan Rhythmic Auditory Stimulation Dalam Meningkatkan Keseimbangan Berdiri Dan Fungsional Berjalan Pada Pasien Pascastroke. Jurnal Fisioterapi, 15 No. 2, 84-94.

Nisa, Q., \& Maratis, J. (2019). Hubungan Keseimbangan Postural Dengan Kemampuan Berjalan Pada Pasien Stroke Hemiparesis, 19, 83-89.

Reynolds, R. F., \& Day, B. L. (2005). Visual guidance of the human foot during a step. 
JPhysiol, 2, 677-684. https://doi.org/10.1113/jphysiol.2005.095 869

Roerdink, M., Lamoth, C. J. C., Kordelaar, J. Van, Elich, P., Konijnenbelt, M., Kwakkel, G., \& Beek, P. J. (2009). Treadmill Walking After Stroke, 668678.

Ryan, S. (2020). Dynamic-Gait-Index. Retrieved from https://www.sralab.org/rehabilitationmeasures/dynamic-gait-index.

Sanchez, JG. Amenguel, JL., Rojo, N. (2013). Plasticity in the sensorimotor cortex induced by Music-supported therapy in stroke patients: a TMS study, 7(September), 1-11. https://doi.org/10.3389/fnhum.2013.0049 4

Sejdic, E., Fu, Y., Pak, A., Fairley, J. A., \& Chau, T. (2012). The Effects of Rhythmic Sensory Cues on the Temporal Dynamics of Human The Effects of Rhythmic Sensory Cues on the Temporal Dynamics of Human Gait, (August). https://doi.org/10.1371/journal.pone.004 3104

Sidaway, B., Anderson, J., Danielson, G., Martin, L., \& Smith, G. (2006). Effects of Long-Term Gait Training Using Visual Cues in an Individual, 86(2), 186194.

Son, G., \& Hyo Jeong Ryu. (2016). Effects of gait training with rhythmic auditory stimulation on gait ability in stroke patients, 1403-1406.

Suh, J. H., Han, S. J., Jeon, S. Y., Kim, H. J., Lee, J. E., Yoon, T. S., \& Chong, H. J. (2014). Effect of rhythmic auditory stimulation on gait and balance in hemiplegic stroke patients. Neurorehabilitation, 193-199. https://doi.org/10.3233/NRE-131008

Teasell, R., Hussein, N., Mcclure, A., \& Meyer, M. (2014). Leading opinion Stroke: More than a ' brain attack .' International Journal of Stroke, 9(February), 188-190. https://doi.org/10.1111/ijs.12233

Teasell, R. W., Foley, N. C., Bhogal, S. K., \& Speechley, M. R. (2003). An EvidenceBased Review of Stroke Rehabilitation, 10(1), 29-58.

Thaut, M. H., Leins, A. K., Rice, R. R., Argstatter, H., Kenyon, G. P., Mcintosh, G. C., Fetter, M. (2007). Rhythmic Auditory Stimulation Improves Gait More Than NDT/Bobath Training in Near-Ambulatory Patients Early Poststroke: A Single-Blind, Randomized Trial,455-459. https://doi.org/10.1177/15459683073005 23

World Health Organization. (2018). The top 10 causes of death. Retrieved from https://www.who.int/news-room/factsheets/detail/the-top-10-causes-of-death. 